\title{
Screening of Alleopathic Activity of the Leaves of Nicotiana plumbaginifolia Viv. on Some Selected Crops in Aligarh, Uttar Pradesh, India
}

\author{
Waseem Mushtaq ${ }^{*}$, Quratul Ain, Mohammad Badruzzaman Siddiqui \\ Department of Botany, Aligarh Muslim University, Aligarh, India \\ Email address: \\ wsmmushtaq61@gmail.com(W. Mushtaq) \\ ${ }^{*}$ Corresponding author
}

\section{To cite this article:}

Waseem Mushtaq, Quratul Ain, Mohammad Badruzzaman Siddiqui. Screening of Alleopathic Activity of the Leaves of Nicotiana plumbaginifolia Viv. on Some Selected Crops in Aligarh, Uttar Pradesh, India. International Journal of Photochemistry and Photobiology. Vol. 2, No. 1, 2018, pp. 1-4. doi: 10.11648/j.ijpp.20180201.11

Received: July 13, 2018; Accepted: July 26, 2018; Published: August 20, 2018

\begin{abstract}
Nicotiana plumbaginifolia Viv. is one of the fastest growing weed. It belongs to family Solanaceae. Sesquiterpenoid phytoalexins have been reported to be the chief components of secondary metabolites this family produces which are responsible for allelopathy. Every year due to its lush growth in the crop fields, $N$. plumbaginifolia as a weed leads to the destruction of thousand tons of crops around the globe. In the present study allelopathic effect of its leaf extract ( $2 \%, 6 \%$ and $10 \%$ ) on percent seed germination of 4 selected local crops of Aligarh (Pisum sativum L, Raphanus sativus L, Triticum aestivum L and Oryza sativa L), on its own seeds and its effects on the soil (control soil, rhizosphere soil of Nicotiana and leached soils) was studied. After eight days of incubation at room temperature, it was found that among the four plants Oryza sativa was most affected with zero percent seed germination with 2, 6 and $10 \%$ of the leaf extract. Maximum percent of seed germination $(80 \pm 10)$ was recorded with Pisum sativum at 2\%. Nicotiana leaf extract was found autotoxic to its own seeds at 6 and $8 \%$ respectively. After 10 days of treatment, an increment of $\mathrm{pH}$ from control soil ( $\mathrm{pH}$ : 7.10) to rhizosphere soil of the Nicotiana ( $\mathrm{pH}$ : 7.28) was reported. Organic carbon, potassium and nitrogen also follow the same trend whereas the EC $(0.44 \%)$ and $\mathrm{P}(13 \mathrm{Kg} /$ hectare $)$ were found the maximum in leaf leached soil.
\end{abstract}

Keywords: Allelopathy, Leaf Extract, Nicotiana, Seed Germination

\section{Introduction}

The term allelopathy was first described by Molisch [1], as a mean of beneficial and detrimental chemical interaction among plants, including microorganisms. Based on the Molisch concept, Rice [2] defined allelopathy as any direct or indirect positive or negative effect of one plant on the other (including the microbes) through the release of chemicals (allelochemicals) into the environment. Allelochemicals are nothing but secondary metabolites that are primarily produced from therapeutic and aromatic plants [3]; the following have been recognized-alkaloids, glycosides, phenolic acids, flavonoids, terpenoids, glucosinolates and coumarins. These chemical substances (Phytotoxic) are known to be exuded by plants to decrease sprouting or growth of the other plants; allelopathic effects of these compounds are often noted to happen early in the life cycle, causing inhibition of seed germination and seedling development. These compounds present a wide extent of mechanisms of action and interpretations of mechanisms of performance are complicated by the fact that particular compounds can have numerous phytotoxic effects [4].

Nicotiana plumbaginifolia Viv. is one of the most abundant species of the genus Nicotiana of the family Solanaceae [5]. Waseem and Siddiqui [6] have reported detailed allelopathic potential of Solanaceae plants. Common name Tex-Mex Tobacco is an annual herb grows 1-3 $\mathrm{ft}$ tall and the stem is slender. The leaves at the base are obvate or oblanceolate, 15-23 cm long; the lower ones are round-ovate, without a stalk, the margin is wavy, pointed, usually twisted, with the base clutching the stem. The leaves of upper stem are reduced, lance-like to linear-lanceolate with margin 
intensely wavy. The inflorescence is a false raceme possessing a 3-7 mm long stalk. Sepals are unequal, 4-8 mm long, linear. Flowers bear a long thin flower-tube, sharply splaying open into petals which are ovate, acute. The tube is pale green or purplish, long and slender, 3.5-4.5 cm long, 1.5-2 mm wide. Tex-Mex Tobacco grows worldwide, however, is native to Mexico, parts of the Caribbean, and western and southern South America, and has been naturalized in the state of Florida [5].

A survey of Aligarh district of Uttar Pradesh, India confirms that the plant is mainly found in moist soil along the roadside, shades of buildings and in crop fields as a weed.

$N$. plumbaginifolia is a common weed rich in allelochemicals [7]. It synthesizes a number of secondary metabolites of phenol, tannins and polyphenol classes, mostly as glycosides The main polyphenols found in the plant are chlorogenic acid (3-caffeoylquinic acid) and rutin (quercitin-3-rhamnosidoglucoside). Other polyphenols stated are quercitin, isoquerciterin, kaempferol glycosides, quinic acid, shikimic acid and scopoletin (7-hydroxy-6-methoxy coumarin) [8]. It is also rich in alkaloids in the form of pyridyl-pyrrolidines and pyridyl-piperidines; the chief alkaloids are nicotine, nornicotine, $\mathrm{N}$-acetylnornicotine, anabasine and anatabine [9]. Furthermore, the same author has addressed the reports of $\mathrm{N}$-carbethoxynornicotine found in cell-suspension cultures of $N$. plumbaginifolia as a metabolite of nornicotine [9]. As its allelochemicals lead to the destruction of the crops, the current investigation was attempted to assess the allelopathic potential of the leaf extracts of $N$. plumbaginifolia on 4 different selected cultivated crops and on its own plants (auto-toxicity) at in vitro followed by its effect via rhizosphere soil experiment in vivo.

\section{Materials and Methods}

\subsection{Collection of the Plant Material}

The leaves of Nicotiana plumbaginifolia Viv. were freshly collected from many sites in Aligarh, Uttar Pradesh $\left(27^{\circ}\right.$, $29^{\circ}$, to $28^{\circ}, 10^{\circ}$ north latitude and $77^{\circ}, 29^{\circ}$ to $78^{\circ}, 38^{\circ}$ east longitude), at a distance of about $126 \mathrm{Km}$ from India's capital New Delhi. Seeds of the 4 different plants; Pisum sativum, Raphanus sativus, Triticum aestivum and Oryza sativa, were purchased from NBPGR, New Delhi, India.

\subsection{Preparation of Leaf Extract}

The leaf extract from the collected leaves of Nicotiana was prepared using the protocol of Netsere and Mendesil [10] with desired modifications. The osmolality of extract was measured with vapour pressure osmometer (VAPRO 5520). It varied between 104-108 m mol kg-1 that did not induce any osmotic effect, i.e. exosmosis in our test plant. The leaf extract was filtered through Buchner funnel with Whatman filter paper no.1 and was stored at room temperature under the dark condition for 24 hours for further use. After the said time different concentrations $(2 \%, 6 \%$ and $10 \%)$ of the leaf extract were prepared by adding double distilled water.

\subsection{Assessment of the Allelopathic Effect of the Leaf Extracts of N. plumbaginifolia}

To assess the allelopathic effect of the leaf of $N$. plumbaginifolia on the seeds of 4 different plants, following parameters were studied:

1. Effect of the leaf extract of $N$. plumbaginifolia on percent seed germination of the selected plant seeds in vitro.

2. Effect of the leaf extract of $N$. plumbaginifolia on the soil in vivo.

\subsection{Effect of the Leaf Extract of $N$. plumbaginifolia on Seed Germination of the Selected Plant Seeds (in Vitro)}

\subsubsection{Germination Assay}

Surface sterilization of seeds: Ten seeds of each plant in triplicate were sterilized with $0.1 \% \mathrm{HgCl}_{2}$ solution $(0.5 \mathrm{~g}$ $\mathrm{HgClCs}$ powder was dissolved in $500 \mathrm{ml}$ distilled water) for $5 \mathrm{sec}$ [11]. The surface sterilized seeds were washed with sterilized distilled water in laminar air flow (Microfilt, India) 4-5 times before using for the germination assay.

Seeding of the seeds in Petri plates for germination: Three concentrations $(2 \%, 6 \%$ and $10 \%)$ of the leaf extract were used to check the allelopathic effect of $N$. plumbaginifolia on the sterilized seeds of 4 plants. In control, distilled water was added. The seeds were aseptically planted in the sterilized Petri-plates (Borosil) with germination paper. All the three concentrations of the $\mathrm{N}$. plumbaginifolia leaf extract were applied to the seeds of each plate (triplicate) except the control. All the plates were incubated at room temperature for 8 days and each plate was watered $(10 \mathrm{ml})$ regularly under aseptic conditions. After the 8th day, the percent germination of the seeds, average (triplicate) and standard deviations were calculated using one-way analysis of variance (ANOVA).

\subsubsection{Effect of the Leaf Extract of N. plumbaginifolia on the Soil in Vivo}

The leaf extract of the $N$. plumbaginifolia (10\%) were mixed with plant-free soil and its physicochemical analysis was carried out along with the rhizosphere soil of Nicotiana, garden soil and normal soil (N. plumbaginifolia free soil) to check the level of allelochemical effect of the leaf extract of the N. plumbaginifolia on the soil. So, following key physicochemical characteristic of the soil $(\mathrm{pH}$, electrical conductivity, organic carbon percentage; N, P, and K content) were analyzed.

\subsubsection{Auto Toxicity of the Nicotiana}

Allelopathic effect of the Nicotiana leaf extract on its own seeds was also checked. Similar to other seeds treatment, Nicotiana seeds were also treated with $2 \%, 6 \%$ and $10 \%$ of the Nicotiana leaf extract and percent germination was determined along with the control.

\subsection{Statistical Analysis}

All the experiments were performed in triplicates. One way analysis of variance (ANOVA) from SPSS version 16.0 
was used to test the significant difference of all the data recorded in the studies. The data are presented in the form of mean with standard deviation and considering $\mathrm{p}$ values < 0.05 as significant. All results were statistically analyzed through Duncann Multiple Range Test (DMRT).

\section{Results and Discussions}

\subsection{Assessment of the Allelopathic Effect of the Leaf Extracts of N. plumbaginifolia}

After eight days of incubation at room temperature the percent germination was calculated. The details of the percent seed germination plant wise are given below:

1. Pisum sativum: The seeds of this plant showed normal germination at all concentrations with respect to control except for the $10 \%$ concentration where only $15 \pm 5 \%$ germination was recorded. (Figure 1).

2. Raphanus sativus: This plant shows normal germination percentage in control, but at $6 \%, 100$ percent inhibition $(0.00 \pm 0.00 \%)$ of seed germination was observed (Figure 1).

3. Triticum aestivum: Strong allelopathic effect of Nicotiana plumbaginifolia leaf extract was recorded in this plant at $2 \%, 6 \%$ and $10 \%$ concentration and $0.00 \pm 0.00 \%$ germination was recorded (Figure 1).

4. Oryza sativa: In $2 \%, 6 \%$ and $10 \%$ concentrations, seeds showed the complete inhibition of seed germination $(0.00 \pm 0.00 \%$ germination) hence strong allelopathic effect was documented (Figure 1).

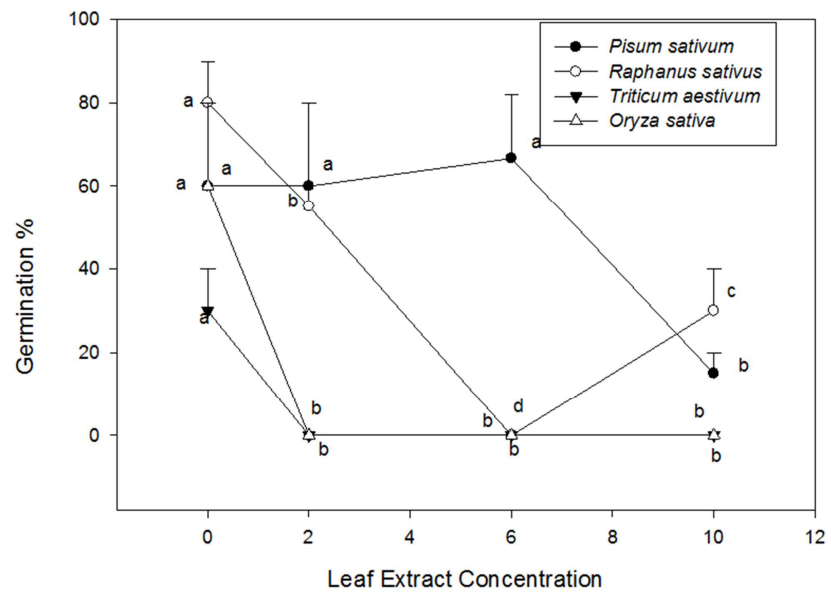

Figure 1. Effect of leaf extract of $N$. plumbaginifolia on seed germination of Pisum sativum, Raphanus sativus, Triticum aestivum and Oryza sativa. Significance difference at $p<0.05$ represented by different subscript symbols along a curve among themselves applying DMRT, vertical bars represent standard deviation.

\subsection{Effect of the Leaf Extract of $N$. plumbaginifolia on the Soil in Vivo}

After 10 days of the treatment the rhizosphere soil of $N$. plumbaginifolia along with garden soil and normal soil were analyzed. The physicochemical properties of a soil sample such as $\mathrm{pH}$, electrical conductivity, organic carbon content, phosphorus $(\mathrm{P})$, potassium $(\mathrm{K})$, and nitrogen $(\mathrm{N})$, (Table 1) of the soils (control soil, leaf leached soil and rhizosphere soil of Nicotiana) reported the increment of $\mathrm{pH}$ from Control soil (pH: 7.10) to rhizosphere soil of the Nicotiana ( $\mathrm{pH}: 7.28$ ). Organic carbon, $\mathrm{P}$ and $\mathrm{N}$ also follows the same trend whereas the EC $(0.49 \%)$ and $\mathrm{P}(13 \mathrm{Kg} /$ hectare $)$ were found the maximum in leaf leached soil.

Table 1. Physiochemical analysis of the soils.

\begin{tabular}{lllll}
\hline \multirow{2}{*}{ S. No. } & \multirow{2}{*}{ Parameter } & \multicolumn{2}{l}{ Type of soil } \\
\cline { 3 - 5 } & & Control & Leaf-leached & Rhizosphere \\
\hline 1 & $\mathrm{pH}$ & 7.10 & 7.10 & 7.28 \\
2 & $\mathrm{EC}($ misa cm $)$ & 0.26 & 0.49 & 0.21 \\
3 & Organic carbon & 0.24 & 0.78 & 1.05 \\
4 & $\mathrm{~N}(\mathrm{Kg} /$ hectar $)$ & 168.00 & 546.00 & 735.00 \\
5 & $\mathrm{P}(\mathrm{Kg} /$ hectar $)$ & 11.84 & 13.00 & 12.94 \\
6 & $\mathrm{~K}(\mathrm{Kg} /$ hectar $)$ & 651.65 & 683.34 & 1017.08 \\
\hline
\end{tabular}

\subsection{Auto Toxicity of the Nicotiana}

The leaf extract at $2 \%$ do not show much effect on the percentage of the seed germination as compared to control whereas increasing concentration of the leaf extract lead to inhibition of seed growth and no seed germination was recorded at $8 \%$ (Figure 2). The results (Figure 2) show that Nicotiana does possess the auto-toxic activity.

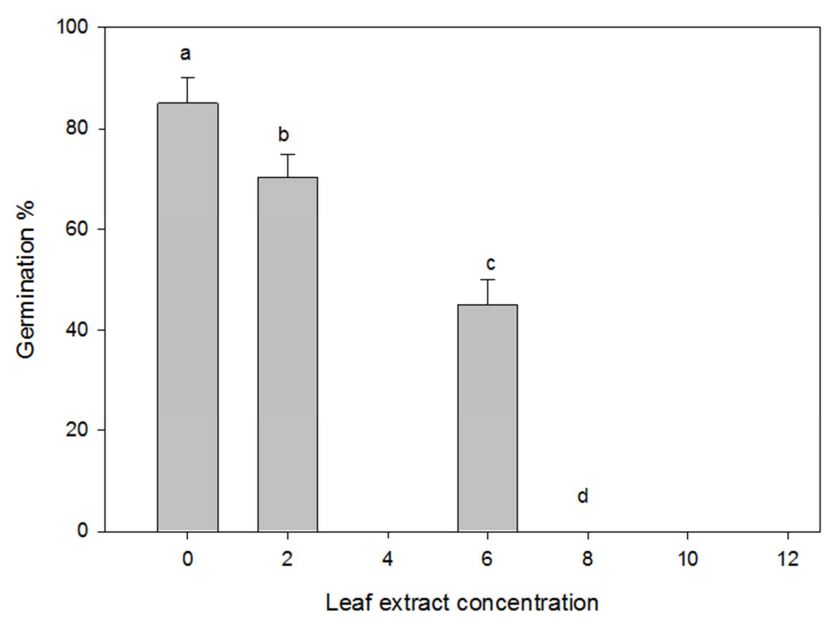

Figure 2. Autotoxic activity of leaf extract of $N$. plumbaginifolia Viv. on germination percentage. Significance difference at $p<0.05$ represented by different subscript symbols along a bar among themselves applying DMRT, vertical bars represent standard deviation.

The present study documented the allelopathic potential of Nicotiana leaf extracts on the percent seed germination of the four selected crops (Pisum sativum, Raphanus sativus, Triticum aestivum and Oryza sativa). Further, the physicochemical properties of soil, the process of leaf exudation, leaf leachates of the Nicotiana are very important. By this process numerous secondary metabolites are released from the leaf parts, they altered the physicochemical properties of soil, and this altered soil is due to secretion of allelochemicals, which enhance the constituent of soil by using the mechanism of allelopathy. In the previous studies [7], shoot extract of the Nicotiana plumbaginifolia Viv. was used to assess the level of allelopathic effect on the seed 
germination and seedling growth of Zea mays. They reported a delay in seed germination and the delay was proportional to the concentration of leachate [7]. Our result is in agreement with them, we reported zero percent seed germination in case of Triticum aestivum and Oryza sativa at all the three $(2 \%$, $6 \%$ and $10 \%$ ) concentrations. Leachate was inhibitory in its higher concentration as reported by Singh et al. [12] Higher concentrations of allelochemicals influence the physiological processes during germination. Higher concentrations of alkaloids cause slowing down the utilization of food reserves [13]. A possible indirect association between lower germination rate and allelopathic inhibition may be the result of inhibition of water uptake [14] and modification in the synthesis/ activity of gibberellic acid (GA) [15]. Physicochemical properties of soil of $N$. plumbaginifolia is altered during release of some secondary metabolites, allelochemicals by the process of leaf exudation, volatilization, decomposition of residues and rhizosphere soil also shows high rate of physicochemical properties like electrical conductivity, $\mathrm{pH}$; organic carbon, $\mathrm{N}, \mathrm{P}$ and $\mathrm{K}$ content as compared to normal soil and control soil. Allelochemicals are capable of alleviating the physiochemical properties of soil [16].

\section{Conclusion}

Based on the present study it will be wise to conclude the leaf extract of the $N$. plumbaginifolia does possess allelopathic effect. Besides affecting the other plants, this plant also reported autotoxic effect on its own species. Nicotiana leaf produces allelochemical(s) and leads to an increase in the contents of organic carbon and nitrogen in the rhizosphere soil of Nicotiana compared to that of control and leaf leached soil. Due to its strong allelopathic potential Nicotiana may lead to huge loss of agricultural production per annum if not handled properly.

\section{Declaration}

The authors do not have any conflict of interest.

\section{References}

[1] Molisch H. 1937. Der Einfluss einer Pflanze auf die andere Allelopathie, Fischer, Jena, Germany.

[2] Rice E L. 1984. Allelopathy, 2nd ed, academic press, New York.

[3] Delabys A, Ancay A and Mermillod G. 1998. Recherch d'especes vegetdles a proprietes allopathiques Annales dela 17th Conference de Columa, 9, 10, 11 Dijon (Souspresse).
[4] Einhelling F A. 2002. The physiology of allelochemical action: clues and views. In: Allelopathy, from Molecules to Ecosystems (Eds.: Reigosa, M. J., Pedrol, N.). Science Publishers, Enfield, New Hampshire.

[5] Knapp S and Clarkson J. 2004. 1642 Proposal to Conserve the Name Nicotiana plumbaginifolia against N. pusilla, N. humilis and N. tenella (Solanaceae). Taxon 53(3): 844-846.

[6] Mushtaq W and Siddiqui MB. 2018. Allelopathy in Solanaceae plants. Journal of Plant Protection Research 58(1): $1-7$.

[7] Singh A., Singh D., Singh N. B. 2009. Allelochemical stress produced by aqueous leachate of Nicotiana plumbaginifolia Viv. Plant Growth Regulation 58 (2): 163-171.

[8] Anonymous. 1962. The wealth of India, raw materials, Vol. VII, CSIR Publications, New Delhi, India, 46.

[9] Eckart E. 2008. Solanaceae and Covolvulaceae: Secondary Metabolites. Springer- Verlag Berlin Heidelberg, pp 74.

[10] Netsere A and Mendesil E 2011. Allelopathic effects of Parthenium hysterophorus L. aqueous extracts on soybean (Glycine max L.) and haricot bean (Phaseolus vulgaris L.) seed germination shoot and leaf growth and dry matter production. Journal of Applied Botany and Food Quality 84: 214-222.

[11] Maharjan S, Shrestha B B and Jha, P K. 2007. Allelopathic effects of aqueous extract of leaves of Parthenium hysterophorus L. on seed germination and seedling growth of some cultivated and wild herbaceous species. Scientific World, 5(5), 33-39.

[12] Singh A., Singh D., Singh N. B. 2015. Allelopathic activity of Nicotiana plumbaginifolia at various phenological stages on sunflower. Allelopathy Journal 36 (2): 315-325.

[13] Einhelling F A. 1995. Mechanism of action of allelochemicals in allelopathy. In: Inderjit, Dakshini KMM, Einhelling FA (eds) Allelopathy, organisms, processes and applications, ACS symposium series, 520. American Chemical Society, Washington, DC, pp 96-116.

[14] Tawaha A M and Turk M A 2003. Allelopathic effects of black musard (Brassica nigra) on germination and growth of wild barley (Hordeum spontaneum). Journal of Agronomy and Crop Science 189:298-303.

[15] Olofsdotter M 1998. Allelopathy in rice. In: Olofsdotter M (ed) Proceeding of the workshop on allelopathy in rice, 25-27 Nov. 1996. Manila, Philippines, International Rice Research Institute.

[16] Dogra K S and Sood S K. 2012. Phytotoxicity of Parthenium hysterophorus residues towards growth of three native plant species (Acacia catechu willd, Achyranthes aspera L. and Cassia tora L.) in Himachal Pradesh, India. International Journal Plant Physiology and Biochemistry 4(5): 105-109. 